\title{
A QUESTÃO PELO HUMANO: ENTRE A TÉCNICA E A PRÁXIS ${ }^{1}$
}

\author{
Ecio Elvis Pisetta \\ Universidade Federal do Estado do Rio de Janeiro
}

Resumo: 0 texto tem como propósito levantar algumas reflexões acerca do ser humano e de sua compreensão predominante de "atividade" em nossa época contemporânea sob 0 predomínio da ciência e da tecnologia. Também prepararemos modestamente, o ambiente a partir de onde esta questão possa adquirir sentido filosófico. Para isso nos perguntaremos pelas condições históricas e/ou metafísicas responsáveis por este predomínio. E, na base disso tudo, explicitaremos certa compreensão primária e exemplar de ser humano, a partir da qual algo como a ciência se torne visível ontologicamente sem se confundir com esclarecimentos de ordem meramente técnica e metodológica próprios destas pesquisas.

Palavras-chave: Prática, teoria, ciência, Heidegger, Koyré.

\begin{abstract}
Our text aims to raise some reflections on the human being and its predominant understanding of "activity" in our contemporary time under the dominance of science and technology. We will also prepare modestly the environment from where the question can acquire philosophical sense. For such we ask ourselves by historical and / or metaphysical conditions responsible for this dominance. And, at the basis of it all, we make clear a primary understanding and exemplary one of the human being, from which something as science becomes visible ontologically without confusing it with the clarification of technical and methodological procedures own of these researches.
\end{abstract}

Keywords: Practice, theory, science, Heidegger, Koyré.

\footnotetext{
1 Reelaboração de palestra proferida no dia 30 de novembro de 2013 com o título "O humano entre a técnica e a praxis", durante o "I Encontro de Pesquisa Interfaces: técnica, arte e questões ético-políticas no pensamento contemporâneo", da Unirio.
} 


\section{Introdução}

O texto tem como propósito levantar algumas reflexões acerca do ser humano e de sua compreensão predominante de "atividade" em nossa época contemporânea sob o predomínio da ciência e da tecnologia. Necessitaremos também preparar, modestamente, o ambiente a partir do qual a pergunta diretriz possa adquirir sentido filosófico. Para isso investigaremos as condições históricas e/ou metafísicas responsáveis por este predomínio. Como base disso explicitaremos certa compreensão primária e exemplar de ser humano, a partir da qual algo como a ciência se torne visível ontologicamente sem se confundir com esclarecimentos de ordem meramente técnica e metodológica próprios destas pesquisas. Com este esforço pretendemos, rudemente, levantar esta problemática e nos admirar com a questão acerca do ser humano.

Estas considerações são atravessadas por uma ambiguidade que, a nosso ver, expressa a estrutura humana de ser em um mundo de relações. De que ambiguidade se trata? Ora, o ser humano - e aqui recordamos as reflexões heideggerianas - compreende-se sempre "sendo" de alguma maneira. Desde os anos 20 do século passado o filósofo alemão Martin Heidegger ocupou-se com este dado fenomenal, de que o ser humano, sendo efetivamente de alguma maneira, já sempre elaborou uma autointerpretação de seu ser, à revelia de uma consciência explícita da mesma. Assim, no modo de ser efetivo, isto é, enquanto praxis, atividade, o ser humano já se autointerpretou e interpretou o mundo, já se compreendeu e compreendeu os entes em seu entorno. Por isso, em algum grau, não é cego, isto é, lida, age, faz alguma coisa, e não pode não fazer. No entanto, esta compreensão "prática" fundamental não se torna visível sem mais. Em geral permanece desconsiderada sob o predomínio de outros afazeres, tanto daqueles ligados às ciências humanas quanto às ciências naturais. Mas, sobretudo, daqueles ligados ao domínio técnico e científico. Este domínio, essencialmente prático-funcional, não carece de nenhum questionamento acerca de sua teoria e prática, exceto aqueles de ordem metodológica e funcional. Assim, visualizamos a tendência deste trabalho: levar em conta a compreensão fundamental do homem como "práxis, lida" - esta sempre nos servirá como orientação - mas se preocupar ou visar, principalmente, à necessidade de uma descrição derivada ou secundária de prática, aquela que caracteriza o domínio técnico e científico. Pois na técnica e na ciência a vida humana é também uma "prática", mas não de modo primário e/ou elementar. Justificamos, desta forma, a necessidade de elaborarmos algumas investigações de cunho histórico e metafísico. 
Qual é o modo dominante de atividade, de fazer ou agir, em nosso tempo? Em que sentido a praxis dominante não corresponde ao modo de agir fundamental do humano? Assim expressou-se a ambiguidade anunciada: o modo de ser do humano é ação, atividade, afazer. E isto num sentido que antecede, ontologicamente, toda consciência e toda racionalidade científica em sentido moderno. Mas este sentido prévio permanece sempre e saudavelmente em questão à medida que habitamos uma época de nosso ser onde a medida de toda práxis é dada pela ciência e pela tecnologia. Se, por um lado, fazemos e não podemos não fazer, não praticar, por outro, como aí, nestes afazeres, somos e estamos? De que modo a ciência e a tecnologia determinam, atualmente, a compreensão de nosso ser enquanto atividade e, por extensão, de toda atividade possível? Como, historicamente, impôs-se este predomínio? Qual o seu alcance e limites? Quais as consequências deste predomínio na vida efetiva do ser humano? Uma discussão desta espécie preparará um caminho para que tanto a questão pela ciência quanto a questão pelo modo de ser do humano possam ser mais bem colocadas. Nosso esquema de trabalho: 1. Questões norteadoras; 2. Que quer dizer "entre"? 3. Considerações existenciais para uma definição de práxis. 4. Ciência moderna: compreensão existencial e positiva. 5. A teoria e a prática científicas. 5.1. A orientação científica na modernidade. 5.2. A mente concipio de Galileu. 5.3. A experimentação ou o casamento da mente com a natureza. 5.4. A ação a partir da experimentação: a ação planejada. 6. Considerações finais: a ação vantajosa.

\section{Questões norteadoras}

O que é o ser humano no predomínio da técnica e da ciência? Se, a partir da filosofia contemporânea, não devemos mais pensar o ser humano como o fez a tradição (pensada de modo genérico) em termos de causas, substâncias, essências, devemos perguntar: há, então, outra maneira de pensar o ser humano? Ora, a partir de sua ação, de sua atividade. Diversos autores deslocam - e isto possui um sentido ontológico específico - a discussão das causas, substâncias, essências, que sempre se perguntam pelo "o que é" (quid, quidditas) para o "como é". Martin Heidegger é um destes pensadores. Mas o "como" não é o deslocamento de enfoque dentro do mesmo nível, da coisa específica para seu mero processo, isto é, em vez de se perguntar pelo "que é" opta-se pelo "como é"! O problema parece ser de outra ordem.

Um modo de explicar e de justificar este deslocamento seria o seguinte: a descrição do modo de ser do humano - seu "como" - impõe-se 
devido à descoberta de que antes do ser humano poder ser definido de alguma maneira ele já “é”, já está sendo ou existindo efetivamente num mundo, já sempre elaborou uma interpretação de si mesmo e do mundo que o rodeia. Então, quando perguntamos pelo que é o ser humano, ou por qualquer ente mundano, a bem dizer, estaremos a fazer uma pergunta tardia (Cf., HEIDEGGER, 1997, p. 27; 29). E, por quê? Porque antes, de alguma maneira, o ser humano já é, já atua, já se encontra em alguma relação possível. Como, então, perguntar adequadamente por um determinado "objeto" - homem e mundo - quando este mesmo "objeto" já está antecipadamente presente na própria pergunta, ou seja, na possibilidade de formular esta mesma pergunta? Então não cabe mais este modo de questionar que toma a realidade como simplesmente dada. Impõe-se a necessidade de outro modo de perguntar e de responder, de investigar, modo esse que se caracteriza, sobretudo, por ser uma descrição, isto é, por se ocupar de tornar, antes de qualquer coisa, transparente para o pensamento o modo de ser prévio acenado. Assim, a pergunta em termos de "como é" e não meramente "o que é" encontra pequena justificativa.

Como pensar esta situação primordial da condição humana em meio ao predomínio da racionalidade científica? Descrevendo algo desta racionalidade. Partindo da situação de fato em que nos encontramos, buscaremos torná-la transparente para nós. Mas a perspectiva a partir da qual esta situação adquirirá visibilidade terá como fundo aquela estrutura prévia já apontada.

Como é o ser humano atual? Ele deve ser pensado não meramente como agente criador - aquele que é autor da técnica, senhor da natureza mas também como produto de sua própria atividade técnico-científica. Fazendo, faz-se a si mesmo. Tamanha consciência e necessidade de questionamento não se impuseram de imediato. Moramos numa época em que a expressão "senhor da natureza" nos atinge de modo paradoxal. Neste sentido o ser humano se mostra também como explorado, como o ente que se torna disponível numa cadeia de produção (Cf. HEIDEGGER, 2002, p. 30), mesmo sem se dar conta, ou, por outra, como funcionário (Cf. FLUSSER, 2002, p. 83-89). Tais compreensões (disponível, explorado, funcionário, sujeito e objeto, etc.) justificam-se, existencialmente, pelo seguinte raciocínio: o ser humano descobre e cultiva seu ser, sendo, isto é, fazendo, agindo de determinada forma. Nem antes nem depois. É na ação ou na atividade que reside o ponto central para tornarmos visível seu ser. Mas de que ação se trata? Daquela que predominou na modernidade sob o manto das ciências e da tecnologia para o domínio da natureza? Ou, desta mesma atividade "estendida" para além da natureza, isto é, para a cultura? Pois o cientista natural, fazendo ciência, descobre a natureza e a si mesmo, 
isto é, cultiva uma determina compreensão de si e do mundo. Então, como estamos a pensar a ação, a atividade? A ação ou atividade que se expressa no predomínio técnico e científico corresponde "sem mais" ao modo de ser do humano, apresentado em termos de previamente já ser e de já deter uma autointerpretação de si e do mundo antes de toda conceituação científica, por exemplo?

Bem, esta ação planejada encontrou seu surgimento no ambiente racional da ciência moderna como "conversão" da inteligência teórica ao real, da teoria na prática (KOYRÉ, 1991, p. 275). Isto é: um determinado modo de agir construído racionalmente ascendeu e tornou-se o modo de agir exemplar ou modelar. Por isso acabou por orientar unidimensionalmente toda ação efetiva dirigida ao mundo "natural". Este modo de agir teórico se impôs como interpretação dominante não apenas sobre o mundo natural, físico, mas, posteriormente, também sobre mundo social, psíquico, espiritual, etc.

Se a ciência e a técnica forem, de fato, o acabamento da tradição, seu ápice, então nelas o projeto metafísico moderno chegou ao fim. Com isso impõe-se a necessidade de uma compreensão desta que ultrapasse a mera aparência técnica. Pois bem, de que fim se trata? É o que vemos em grau crescente no predomínio das ciências da informação e na compreensão da teoria como

suposição de categorias a que se reconhece apenas uma função cibernética, sendo-lhe negado todo sentido ontológico. Passa a imperar o elemento racional e os modelos próprios do pensamento que apenas representam e calculam (HEIDEGGER, 1983, p. 73).

Qual a origem histórico-metafísica disso tudo? No advento das ciências naturais e, posteriormente, durante o século XIX, com o predomínio do "cientificismo". Neste, os métodos de asseguramento, domínio, controle e constrangimento da natureza foram idealmente estendidos para os âmbitos da vida social, da indústria, da organização social (exército, escola, instituições diversas) bem como de boa parte das ciências humanas nascentes (Cf. p. ex., FOUCAULT, 1988; tb. FLUSSER, 2002). Por outra, os procedimentos nascidos no âmbito da natureza e que objetivavam o controle desta estenderam-se e alcançaram o âmbito do "espírito" ou da cultura. Este fenômeno ficou conhecido como "naturalismo" (Cf. HUSSERL, 1952, p. 9). A consciência destes problemas, desde as primeiras décadas do século XX, gerou crises no fundamento das ciências. Estas trouxeram como resultado proveitoso uma ocupação ciente com os princípios, com os postulados fundamentais e os métodos característicos de cada ciência. Cada uma deveria buscar e encontrar sua identidade segundo suas próprias possibilidades, segundo as possibilidades 
de objetivação pertinentes ao seu campo. Coisa nem um pouco fácil, sobretudo nas ciências naturais. Em toda ciência entendida positivamente ("naturalismo") habita um silêncio e uma falta de investigação acerca de seu ente temático, de seu fundo, do recorte ou da perspectiva que a identificam: as ciências progridem, estão sempre "fora de si", junto aos objetos a serem investigados. Elas nunca ou raramente estão "junto a si", colocando-se numa crise de princípios. Isso, ser continuamente um problema para si mesmo, é coisa da filosofia e não das ciências positivas. No entanto, apesar de todas estas novas visões da ciência, nestes avanços e modificações que merecem a nossa atenção - serve como exemplo os avanços da física quântica - deve-se considerar que a mesma tendência fundamental, longamente cultivada durante a modernidade sob o nome de racionalismo, permanece. Nossas questões assim se justificam. Como pensar o ser humano, seu elemento de humanidade, no mundo técnico-científico? Como pensar teoria e prática a partir desta perspectiva? Será que a compreensão moderna - haurida a partir da experiência técnico-científica - esgota a compreensão de teoria e de prática?

Traçaremos, a seguir, uma breve descrição do que já apontamos como sendo o modo primário e prático de existência do ser humano, prévio a toda atividade racional.

\section{Que quer dizer "entre"?}

Buscamos certo esclarecimento acerca do modo de ser do humano apresentado como atividade. Indicamos que a atividade dominante em nossa época encontra sua orientação no predomínio da ciência e da tecnologia, ou seja, da racionalidade científica. Então esta racionalidade - teórica e prática - é a práxis moderna por excelência? A técnica e a ciência esgotam toda atividade humana? Ou, em tudo isso, encontramos problemas?

Quando perguntamos, grosso modo, pelo lugar do humano "entre" a técnica e a práxis, isto significa que estamos tomados por certa suspeita. Afinal, o que quer dizer "entre"? Significa que o ser humano enquanto atividade não pode ser adequadamente contemplado nem no predomínio da ciência e da técnica e nem no da práxis, por ora entendida como prática em geral? "Entre" significaria, então, por um lado, uma exclusão: nem uma nem outra. Então, o modo de ser do humano residiria num outro lugar, num lugar "entre" uma e outra, um lugar "fora"? Mas que lugar é esse? Como podemos encontrá-lo? Este lugar, que é lugar nenhum, é exatamente a perspectiva a partir de onde é possível visualizar e balizar tanto a técnica quanto a práxis em geral como atividades, como sendo expressão do modo de ser humano. 
Esta perspectiva não pode ser compreendida a partir da oposição ou técnica ou práxis. Uma e outra seriam mal interpretadas em seu ser.

Explicando melhor: a técnica e a práxis em geral são atividades humanas, lugares "práticos" onde o ser humano, de fato, é: ora na pesquisa científica e similares, ora na lida com as coisas, as ferramentas e com os outros. Como o ser humano poderia ser, sem o ser, em alguma atividade? Então, "entre", possui também um aspecto inclusivo, ou seja, o ser humano "é" numa e "é" também na outra; é na técnica e é na lida. Não "ou", "ou", mas "e", "e". E tal constatação nos impõe um problema capital: como é esta inclusão? De que forma a contradição "nem..., nem" nos remete ou nos joga para a unidade do "e..., e"? Pois o fato de o ser humano ser numa e noutra não exclui, mas exige a compreensão acerca do modo de ser desta inclusão. Porque, afinal, isto não significa que o ser humano seja da mesma maneira numa e noutra. Apenas significa que ele é tanto numa quanto na outra, mas de modo distinto, e que não pode não ser numa atividade. A pergunta pelo modo ou jeito, isto é, como o ser humano existe numa e noutra permanece.

$\mathrm{O}$ "entre", este lugar nenhum, nos convida a uma reflexão acerca do modo de ser deste ente que nós somos, "entes privilegiados" na expressão heideggeriana, e que possui um modo de ser "inclusivo", ou seja, "aberto", "disposto", para todo ente, para toda distância e proximidade, para todo lugar. E a compreensão desta possibilidade inclusiva não se encontra nos resultados, não se encontra no afã acumulativo de tudo abarcar segundo uma possibilidade. Antes se encontra num caminho ou curso retroativo, se comparado com os trajetos comuns, enfim, no jeito do humano de ser e não meramente neste ou naquele modo. Isto porque, fundamentalmente, o ser humano é nem, e nem! É neste sentido que o modo de ser atividade clama por uma reflexão. Pois não estamos a nos ocupar de uma mera e indiferente prática, quer a serviço do predomínio técnico e científico, quer a serviço de alguma compreensão simplesmente dada de sociedade e de convivência.

Bem, como podemos nos aproximar deste modo de conceber o humano, a fim de que nosso intento não caia no vazio e no sem sentido? Nosso caminho leva em conta, como uma referência, nossa situação no mundo atravessada pela ciência e pela tecnologia.

\section{Considerações existenciais para uma definição de práxis.}

Até agora perguntamo-nos acerca do modo de ser do humano. Nós o apresentamos como práxis, como atividade. Sentimos a necessidade de esclarecer melhor o sentido em que articulamos o termo praxis. Voltamonos para Ser e tempo - e a seguir o faremos novamente - a fim de buscar 
um esclarecimento a respeito do sentido em que o ser humano pode ser apresentado como "atividade". Vejamos: "Os gregos possuíam um termo adequado para dizer [grifo nosso] as "coisas": pragmata, isto é, aquilo com que se lida (praxis) na ocupação" (HEIDEGGER, 2006, §15, p. 116).

As coisas são aquilo com o que se lida, tanto as coisas corriqueiras e imediatas, quanto as coisas que, a força de repetições e na busca pelo conhecimento, requerem alguma organização teórica, como as mais diversas habilidades ou técnicas. O saber a respeito das coisas - quando nos esforçamos por dizer as coisas - se constrói, igualmente, como uma atividade, mas dependente, primeiramente, daquilo com o que lidamos em nossas mais diversas ocupações. Assim, lidar é, por um lado, "usar" a roupa, o talher, o calçado, o martelo, etc. e, por outro, lidar é também buscar as causas e os princípios responsáveis pelos usos e seus instrumentos, a fim de aprimorá-los (techne, arte). Pois "usamos" sabendo, de alguma maneira, usar. Buscar as causas pode se transformar numa atividade, a teórica, que assume a característica de ser "a atividade" por excelência (episteme, ciência). Mas, devemos ficar atentos, pois por mais que ela busque os porquês e as causas imediatas de determinada arte, ou os porquês e as causas primeiras, o universal, esta atividade, ela mesma, possui algo de tardio. É uma atividade tardia porque buscar as causas, pensar, e dizer o que foi pensado, pressupõe uma ação primeira, uma provocação ou encontro primeiro, ou seja, um modo de ser precedente. Visa-se, com isso, tornar transparente uma hierarquia ontológica, se é que podemos assim nos expressar. Podemos usar as coisas, por exemplo, como qualquer um o faz, isto é, pelo hábito. Mas dessa forma encobrimos o aspecto "ativo" e "criativo" presente em todo uso, aspecto que poderá ser despertado para o saber por meio da atividade teórica em algum grau. Usar, lidar, praticar detém o aspecto de descoberta e de encontro com a realidade. Mas isso não significa que, independentemente desta atividade teórica, a lida efetiva não tenha e detenha seus mecanismos de visão e de teorização inteiramente práticos. Podemos também, cientemente, visar a algum grau de apropriação dos porquês de determinados usos e não de outros. A arte e a ciência antigas estavam nesta direção. Em tudo isso está em jogo uma interpretação constante do "o que", que, de modo fundamental, afeta o saber. Lembramos também, que tudo se torna complicado se, ingenuamente, opomos as coisas e os usos - a lida - como se, em algum momento, estivéssemos fora de todo uso "aprendendo" a usar algo. Pois "as coisas" são aquilo com que se lida na ocupação, em alguma ocupação possível. E elas desafiam nosso saber a partir desta práxis. O ser humano não pode não ser ocupação, atividade, inclusive quando se propõe a aprender algum uso. Ele nunca está em algum 
momento fora desta relação. Assim, uso e coisa, segundo esta compreensão de práxis, mantêm uma conexão ontológica.

A práxis, no sentido aludido, remete ao mundo empírico, précientífico, imediato, de lida ou ocupação com as coisas e com os outros. Esta experiência é de ordem prática. Mas esta mesma experiência remete também ao saber acerca das razões e das causas deste mundo, constituindo uma ciência, uma epistéme. Então, já sempre se lida no espaço e no tempo de uma perspectiva ou visão sempre disponível. Teoria e prática são modos da práxis, de tal forma que o ser humano não pode ser pensado como sendo, num momento, uma e noutro, outra. Ele, simultaneamente, quer o saiba ou não, é uma e outra. Por isso pode ocorrer que, por exemplo, a teoria ou o comportamento teórico se torne uma atividade autônoma, se descole do que comumente se compreende como lida. Mas o foco permanece como sendo a investigação daquilo que pertence a toda relação prática, a toda lida e, por extensão, ao ente em geral. As artes em geral e a ciência antiga, à medida que buscam os porquês e as causas (e a filosofia serve como exemplo), constroem um espaço ímpar de ser, de atividade, e são reconhecidas como tal.

Mas quando falamos aqui e ali que o que caracteriza a ciência e a tecnologia modernas está na racionalidade, no planejamento, no controle e asseguramento, etc., remetemos apenas parcialmente a esta explicação. Pois a arte e a ciência antigas sempre foram, em algum grau, empíricas, isto é, atidas ao mundo natural, sublunar, imperfeito. E a ciência e tecnologia modernas constroem sua autonomia prescindindo desta remissão. A racionalidade científica erige para si uma teoria e uma prática num sentido altamente distinto da antiga e medieval e com propósitos outros (Cf. KOYRÉ, 1991, p. 265-267; 271ss).

Então, como surgiria o comportamento teórico próprio da ciência e da tecnologia? Vejamos alguns pontos orientadores extraídos, sobretudo, de uma interpretação do parágrafo 13 de Ser e tempo de Heidegger (Cf. HEIDEGGER, 2006, p. 106ss). 1. A lida com as coisas, em algum momento, é interrompida, é suspensa (ou porque o instrumento quebrou, ou faltou, ou porque houve alguma alteração imprevista no contexto de atividades, exigindo uma reinterpretação do instrumento, etc.). 2. Quando a atividade é suspensa o ente, a coisa, se apresenta ao saber como algo intrigante, deslocado, separado, descontextualizado. Mas, como se está compreendendo este ente? Na linguagem heideggeriana como algo simplesmente dado, simplesmente existente e destituído de conjuntura. Ele pode ser visualizado "aparentemente" como dotado, por exemplo, de propriedades ou características que pertencem a ele e não a outros. Mas esta possível visualização já se encontra orientada por outro modo de ser - o de 
ser simplesmente dado - distinto do contexto instrumental próprio da lida. 3. Neste sentido, quando a atividade prática é suspensa, são postas em movimento as únicas possibilidades humanas disponíveis, as teóricas, com o objetivo prático de retornar a alguma atividade, quer seja a anterior ou outra. O estado de suspensão contínua pura e simplesmente é insuportável. Assim, aquela visualização do ente como algo puramente dado e, na sequência, aquela caça de propriedades, possui algo de provisório. 4. No entanto, o "questionamento", enquanto pergunta e exploração das possibilidades simplesmente dadas das coisas, dos entes, pode ser elevado à altura de uma atividade autônoma na discussão e organização dos porquês e das causas. Constrói-se um espaço que, durante a suspensão, se aprimora como uma arte autônoma e aprimora a execução de determinada habilidade, quer visando a um fim típico da lida com as coisas, quer visando tão somente à exploração e problematização deste encontro primário para o saber. De certa forma, a arte e a ciência antigas tornam-se visíveis em seu modo de ser, não como alguma prática ou discussão "puramente teórica", mas como movimento de descoberta e apropriação do que se apresenta como realidade. Destaca-se o reconhecimento do mestre e do sábio, inclusive para além de toda finalidade prática.

No entanto, quando pensamos na ciência moderna percebemos que este retorno à atividade se dá de forma distinta, o que não é simples de caracterizar. A bem dizer, nunca há um puro retorno, nem na moderna ciência, nem na técnica e na ciência antigas, à medida que nunca se volta ao mesmo ponto de ruptura e nem da mesma maneira. Se assim pensássemos estaríamos a desconsiderar a condição humana de "saber". Se, por um lado, o pensamento sempre volta à atividade com alguma regra nova aprendida, por outro lado, como esta regra foi obtida e, sobretudo, segundo que interesse será usada? Se foi obtida a partir da natureza, da coisa, do ente, podemos dizer que a regra obedece ao mundo, à natureza, às coisas. Mas, se foi obtida a partir da "ideia", da mente, da razão, da "teoria racional", então podemos dizer que semelhante regra obedece à razão, ao modo de ser autônomo e articulado que se desenvolve e se garante por meio das faculdades "racionais" humanas, tal como a modernidade o fez. Esta segunda direção, a da razão, não se converte numa arbitrariedade, no sentido de que vale ou pode valer qualquer plano. De forma alguma! É preciso que haja um casamento entre o modelo e a natureza, casamento este feito segundo regras racionais. Neste sentido, o pensamento volta à natureza com algo a mais, algo que não foi meramente obtido a partir da reflexão e/ou ponderação empírica. Trata-se de uma ousadia, uma ousadia "tecnológica" tipicamente moderna. Não se visa mais aprender da natureza (“a arte imita a natureza”), mas organizá-la, instruí-la, ensiná-la, submetê-la, 
etc., ou seja, a natureza deve imitar a teoria, a ciência, o saber, em sentido moderno. Esta compreensão se encontra expressa no prefácio à Critica da razão pura de Kant (Cf. KANT, 1994, p. 18; Cf. tb. HEIDEGGER, 2002, p. 24-25). Este problema pode também ser apresentado na linguagem do filósofo V. Flusser, já em fins do século XX:

A questão já não é mais voltada para o que é real, mas sim para o que é conveniente; e então se verifica que não se pode simplesmente aplicar formas convenientes aos fenômenos (no caso, os círculos), a não ser aquelas mais convenientes que harmonizem com eles. Em suma: as formas não são descobertas nem invenções, não são ideias platônicas nem ficções; são recipientes construídos especialmente para os fenômenos ("modelos"). E a ciência teórica não é nem "verdadeira" nem "fictícia", mas sim "formal" (projetam modelos). (FLUSSER, 2007, p. 28).

Desta forma, a teoria que caracteriza a ciência moderna se autocompreende de modo autônomo como o primado da razão (ou da mente) sobre o real, isto é, sobre o mundo imperfeito, natural, sublunar, meramente empírico. E a reflexão acerca desta passagem, isto é, acerca da modificação ocorrida em relação a todo o pensamento anterior, é sempre complexa.

Então, o que distinguiria estes dois modos humanos de ser atividade, que podemos nomear como lida e comportamento técnico e científico? A orientação ou direção "teórica" fundamental. Uma, da experiência ou da prática ou da lida empírica com as coisas para a teoria ou para o saber. E esta se mantém diretamente obediente - ob-audire - àquela. Outra, do saber planejado, esquematizado, racionalizado, dos modelos, para toda experiência com as coisas, no sentido de gerenciar esta experiência, de produzir a experiência ideal, otimizá-la pela condução racional. Percebe-se, neste caso, que é possível construir modelos ideais que possam capturar os fenômenos naturais numa previsibilidade. $\mathrm{O}$ cientista deixa-se guiar pela razão, por um plano seu, e não mais pelos objetos. Para tanto, o sentido do saber se alterou: não mais o conhecimento das causas e dos princípios como referências universais, eternas, ontológicas, mas daqueles porquês que possibilitam, de modo organizado e provisório, garantir um domínio crescente do mundo natural. Determinado modelo, como construção racional, dura enquanto os fenômenos a ele se submetem. Isto é, torna-se possível, assim, realizar a ação desejada, planejada. Interessa este controle 
racional. A natureza enquanto o que tece e acontece ou como refúgio dos deuses, ou como mistério, pertence a outra perspectiva. Estas possibilidades de encontro são vistas, a partir da perspectiva da ciência moderna, como situações provisórias, como dificuldades a serem solucionadas.

Torna-se, para nós, mais clara a polissemia que invade nossa compreensão comum do termo praxis. Esta remete ao modo de ser do humano: o ser humano, antes de tudo, está ou se encontra numa relação com as coisas, sejam elas quais forem. Mas se impõe a pergunta: como é esta relação? Então sentimos a necessidade de descrever este modo de ser, o de ser relação, mesmo que modestamente. Atendendo a esta necessidade encontramos variáveis que apontam para modos de ser distintos e, de certa forma, derivados. São derivados porque não eliminam, mas pressupõem, o modo de ser prévio, o do ser humano já sempre estar remetido a um mundo e, assim, já estar sempre numa relação com as coisas, com os entes: uma práxis. Então a partir desta relação prática primária (que se esquiva quando a opomos à teoria), que é antes de tudo, detecta-se o nascimento de outras práticas. Quando determinada ação efetiva é suspensa, o questionamento ou a teoria é convocado. Então se pode "consertar" o que deu errado e retornar à ação. A bem dizer, nunca se retorna exatamente à ação anterior. Isto porque o saber muito aprende quando é convocado. Podemos, desta forma, visualizar o surgimento ontológico e o desenvolvimento do que conhecemos como habilidade ou técnica ou arte e também da ciência, no sentido da ciência antiga e medieval, por exemplo. Cada arte e cada ciência permanecerão, ainda, ligadas à "natureza" como o espaço maravilhoso e surpreendente em que o ser humano, desde sempre, habita. A natureza, assim compreendida, permanece o referencial original, isto é, o elemento que orienta toda prática e toda teoria. Quando se buscam as causas da natureza para intervir na mesma, então a teoria que ali aparece permanece obediente à natureza.

Mas este comportamento teórico sofre ainda outra modificação, uma modificação que altera o modo como o ser humano descobre o saber e, junto com isso, a prática. A relação com o mundo se transforma, mas não deixa de ser prática. Trata-se, então, do desenvolvimento da teoria como atividade autônoma num sentido distinto da antiga e medieval. Esta teoria - a racionalidade converte-se no princípio ou no ponto de orientação de toda teoria e de toda prática, ou seja, de toda consideração acerca do homem e do mundo.

A partir destas considerações nossas perguntas começam a adquirir o sentido desejado: O que faz da técnica moderna uma práxis possível? Uma resposta a esta pergunta nunca poderá ser meramente encontrada no mero pragmatismo tecnicista. 


\section{Ciência moderna: compreensão existencial e positiva}

Toda ciência nasce de um recorte. $\mathrm{O}$ que foi recortado pode se converter num ente temático sobre o qual ela se debruça, objetivando-o, isto é, interpretando-o. Neste procedimento básico, existencialmente, já se anunciou a estrutura do ser humano como ser-no-mundo. $\mathrm{O}$ homem vive no modo da ciência. Nela, segundo seu modo de ser, o ser humano se relaciona com os outros, com objetos, com produtos, com uma natureza que resulta do conhecimento físico-matemático, e não da experiência empírica junto à natureza. Mas, antes de fazer ciência o homem já fazia outras coisas, já vivia, trabalhava, sofria, amava, guerreava, cultuava, cultivava, produzia, lidava com as coisas, teorizava e experimentava. A própria natureza tornouse visível pela primeira vez a partir deste conjunto de experiências, como aquela que fornece os alimentos, os materiais, os perigos e os benefícios. Ora, a ciência se constitui como um modo de ser no mundo, ou seja, um modo de ser distinto de outros que "recorta" à sua maneira. Quais são as possibilidades ontológicas para que este modo de ser se realize, se imponha, e se distinga de outros modos?

Não precisamos retirar todas as implicações dos enunciados precedentes. Heidegger chama de "manualidade" (Zuhandenheit) o conjunto destas vivências prévias (praxis) ao modo de ser científico e que se tornam conhecidas levando em conta o modo de ser do humano, descrito, por exemplo, em Ser e tempo, na analítica da presença, do Dasein. Já a ciência nasce como uma redescoberta das coisas, destes entes, como seres simplesmente dados (Vorhandenheit) ou simplesmente existentes, isto é, retirando-lhes o aspecto de remissividade e significância próprios da lida com as coisas e impondo-lhes outros. A partir da lida efetiva um ente somente pode ser compreendido numa conjuntura e, nesta, adquire um sentido ou significado. $\mathrm{O}$ modo da ciência impõe uma nova maneira de ler e interpretar o ente - o ente natural e, posteriormente, o ente "cultural" fundada na racionalidade representativa. Esta aciona, então, o ente simplesmente existente para que este possa ser descoberto ou interpretado de modo novo. Um novo jeito de teorizar e praticar ou experimentar as coisas. Vejamos:

A tematização [científica] visa liberar os entes que vem ao encontro dentro do mundo de modo que possam ser "projetados para" uma pura descoberta, isto é, que possam tornar-se objetos. A tematização objetiva. Não é ela que "põe" pela primeira vez o ente (...). Trata-se apenas de compreender que e como a tematização dos entes intramundanos pressupõe a constituição 
fundamental da presença, isto é, o ser-no-mundo. (HEIDEGGER, 2006, §69b, p. 452).

Tendo como base esta citação, podemos dizer o seguinte: Não é a tematização científica que descobre o ente pela primeira vez. Ela libera, isto é, se apropria e interpreta o ente segundo sua perspectiva, segundo seu recorte característico. Ela o objetiva. A ciência é construção. Assim, tematizar, pressupõe um conjunto de coisas que, em geral, permanecem desconsideradas no esforço meramente objetivo das ciências. Isto porque as ciências se direcionam para o objeto e não para ou contra si mesmas. Por isso são chamadas de "positivas". Numa leitura existencial, interpretamos a ciência e a técnica de um modo que elas nunca o farão nem precisam fazêlo. E se o fizessem, deixariam de ser o que são. A leitura existencial, por exemplo, não se contenta com a interpretação antropológica e instrumental da técnica. Pois tal interpretação direciona-se para os entes como meios e/ou fins, ou seja, para a técnica como atividade humana, uma entre tantas. Homem e mundo não são ali adequadamente pensados. Então percebemos um corte teórico, por assim dizer, entre "manualidade" e "ser simplesmente dado". Se, por um lado, um, a bem dizer, não exclui o outro, por outro lado, cada um possui seu jeito de ser. E mais. Segundo este autor, a manualidade possui uma primazia em relação a atitude teórica típica das ciências. De que primazia se trata? Trata-se da constituição fundamental da presença (Dasein), do ser-no-mundo. Nas descrições manuais e pré-científicas se revela de modo imediato o jeito de ser do humano, enquanto que na atitude teórica das ciências o ser humano se mostra apenas de modo mediado, isto é, por meio das representações. Trata-se do conflito entre os existenciais e as categorias.

Em geral, pode-se definir a ciência como o todo de um conjunto de fundamentação de proposições verdadeiras. Essa definição não é completa nem alcança o sentido de ciência. Como atitude do homem, as ciências possuem o modo de ser desse ente (homem). Apreendemos terminologicamente esse ente como presença (Dasein). A pesquisa científica não é o único modo de ser possível desse ente e nem sequer o mais próximo. (HEIDEGGER, 2006, §4, p. 47).

Feita esta breve distinção, nos orientaremos para a teoria e prática nascidas deste modo de ser chamado "ciência". Um modo de ser representativo, mediado, não primeiro, secundário. Através deste esclarecimento poderemos perceber como, em geral, é a nossa prática e a 
nossa teoria. Poderemos com mais direito, adiante, levantar a pergunta se esta teoria e esta prática esgotam toda teoria e toda prática.

E o primeiro dado fenomenal que encontramos para "atividade" é o modo de ser do humano prévio a toda atividade teórico-científica, por exemplo e, por extensão, a toda outra atividade que pressupõe conceitos, símbolos, ideias das mais diversas espécies que foram ou são de alguma forma institucionalizadas. Então, atividade é relação com as coisas, junto aos outros, junto a si mesmo, num mundo, de modo prévio a toda institucionalização. Por isso este modo de ser não pode ser compreendido como "pré-científico" no sentido de ser uma "camada" anterior à ciência reconhecida. Pois, como estaremos a compreender esta camada? A partir do científico? Então não será que estamos a cobrar desta camada primária algum modo institucionalizado de ser, mesmo que não científico ou de outro gênero? Heidegger, ocupado e preocupado em determinar este modo de ser do humano, o Dasein, aqui e ali em sua obra o apresenta como "abertura", como "liberdade", como "poder-ser", como "possibilidade", etc. Antes de toda institucionalização possível o ser humano já está disposto ou aberto para uma relação possível, para toda e qualquer forma de institucionalização. A partir destes apontamentos delineia-se um sentido primeiro em que compreenderemos a prática (atividade, práxis) e um sentido secundário ou derivado. Por certo, nos dois sentidos acontece a existência humana como e enquanto atividade. Mas não da mesma maneira.

\section{A teoria e a prática científicas.}

Sabemos que a técnica e a ciência hoje nos informam infinitamente acerca do ser humano. Elas nos dizem de maneira preponderante quem nós somos, como somos, como fomos, como devemos ser, como seremos. Mas, reside na técnica moderna, neste momento histórico, a última resposta acerca do que nós somos? Em certo sentido, esta mesma técnica já decretou o fim da metafísica, a dispensa ou a perda de sentido daquelas questões extramundanas, insolúveis, que moveram toda tradição. Em seu lugar instaurou a funcionalidade, a cibernética, as hipóteses de trabalho. Tudo é provisório, tudo é processo! Homem e mundo encontram seu sentido nesta cadeia funcional, como aparelhos e a serviço de aparelhos (Cf. FLUSSER, 2002, p. 24-25; Tb. FLUSSER, 2007, p. 41). Que há de mais verdadeiro do que proclamar que tudo é relativo, que tudo está em contínua mudança, que tudo é processo? Por certo, há quem cante que nunca fomos tão avançados (o que lembra o otimismo positivista do século XIX). E, no entanto, não apenas a ficção (a científica, por exemplo), mas os eventos históricos do 
último século, sobretudo, têm cultivado em nós certa suspeita a respeito deste otimismo dominante.

O predomínio da funcionalidade já se estende por todo o globo e de modo crescente. Como salientamos e ainda destacaremos, esta funcionalidade tem suas raízes no advento da ciência moderna. Posteriormente abarcou a vida social. E, mais recentemente ainda, estendeuse e estende-se aos fenômenos psíquicos, aos sentimentos, vontades, modos de pensamento, etc. Buscam-se leis racionais. Pressupõe-se que, se tudo possui um "código" matemático, tudo pode ser "decodificado" e, consequentemente, "recodificado": forma atual do projeto moderno de controle e asseguramento da natureza. Mas a realidade continuamente e saudavelmente oferece resistências.

Essa resistência, a nosso ver, não pode ser interpretada meramente como algum defeito de percurso. Nela anuncia-se algo de fundamental, talvez aquela estrutura prática primária. O ser humano, então, suspeita deste predomínio unidimensional da técnica e da ciência, da cibernética e da funcionalidade. Suspeita do modo como a ciência física, por exemplo, determinou tradicionalmente a realidade. Esta suspeita, inclusive, brota no próprio seio do desenvolvimento científico. Serve como exemplo os questionamentos acerca da realidade que o progresso da física na física quântica nos trouxe (Cf. NICOLESCU, 1999, p. 32).

A técnica, em sua forma moderna, nasce da possibilidade de impor ao real um plano teórico, mental, uma racionalidade. Um conhecimento planejado dos entes. Este modo de ser se assegura do real, controlando-o de forma antecipada, isto é, tornando-o previsível: a realidade será o que antecipadamente planejou-se na razão e, a partir desta, projetou-se. Assim realiza-se uma domesticação da natureza, do real, a partir da razão. $\mathrm{O}$ importante é, então, como o real deve ser - um espelho da razão - e não como ele é. Tenhamos, brevemente, em mente o modo de ser desta imposição - constranger, forçar, interpelar, etc.

Então, a compreensão a que nos submetemos de ciência e de técnica - de tecnologia - é de ordem metafísica ou ontológica. Ali encontramos um jeito ou modo do ser humano viver e existir num mundo. Levando em conta este modo de ser básico no qual e sobre o qual existimos preponderantemente, perguntamos: que é, então, ali atividade? Por um lado esta pergunta parece ser sem propósito! Que sentido tem esta pergunta num ambiente preponderantemente ativo, prático, como o é o mundo científico e tecnológico? Onde predomina esta prática, primado da utilidade, é também onde mais carecemos de uma reflexão adequada. Heidegger nos diz que a concepção instrumental e antropológica da técnica, isto é, dela ser compreendida exclusivamente como um meio e uma atividade humana pode 
ser correta mas não verdadeira, pode ser adequada, mas não nos conduz a uma séria e grave reflexão acerca do que significa o termo "atividade" (Cf. HEIDEGGER, 2002, p. 12). Para entendermos que não é sem mais que compreendemos estas experiências como "atividades", que o ser "atividade" atinge o modo de ser do ente que somos, concentremo-nos no nascimento da moderna experiência da ciência e da tecnologia.

\subsection{A orientação científica na modernidade}

Nós moramos num mundo atravessado pelo que se convencionou chamar de ciência e tecnologia, onde a primeira não se refere simplesmente a conhecimentos teóricos nem a segunda a alguma aplicação prática destes conhecimentos. Ciência e tecnologia referem-se a um único e mesmo fenômeno - a técnica moderna e sua essência - como o filósofo $\mathrm{M}$. Heidegger apresenta em alguns de seus trabalhos (Cf. p. ex., HEIDEGGER, 2002, p. 25), bem como A. Koyré (Cf. p. ex., KOYRÉ, 1991, p. 264-267; $271 \mathrm{ss})$. Ali a tecnologia é interpretada como o próprio télos da ciência moderna e, de um ponto de vista metafísico, como o próprio destino da modernidade. Elas não possuem uma relação causal, onde a tecnologia derivaria da ciência. Nem se considera esta como a mais antiga historicamente, produzindo, em seu processo evolutivo a tecnologia. Ambas precisam ser consideradas dialeticamente. Dessa forma se perceberá que o termo "tecnologia" ultrapassa a aparência maquinal, meramente técnica, de simples aplicação de princípios. Na tecnologia encontramos, por assim dizer, o tema de nosso tempo. Assim, não é a tecnologia que sucede à ciência, mas esta àquela: a "aplicação", ou seja, o fim, é dotado de precedência. Porque no fim realiza-se ou efetiva-se ou culmina o que, aos poucos, vem sendo cultivado desde os primórdios da ciência moderna. Mas, semelhante afirmação pressupõe uma compreensão deste começo da ciência moderna e de como, em seu bojo, a teoria e a prática são pensadas.

Dessa forma, seria também um erro compreendermos esta precedência no sentido de uma mera inversão hierárquica, ou seja, a tecnologia viria antes da ciência. $\mathrm{O}$ que isto significaria? Acaso que a ciência é consequência de algum domínio da fabricação de instrumentos e máquinas, por mais rudimentares que o sejam? A aplicação visada, a tecnologia, não é um mero sucedâneo de alguma teoria nova, bem como a ciência não é a consequência certa de algum desenvolvimento na construção de máquinas. Ficaríamos perdidos num círculo vicioso. $\mathrm{Na}$ tecnologia encontramos o próprio fundo, a própria visão nova das coisas e da natureza. Uma nova visão, porque ela, de alguma maneira, encontrou como princípio algo que a mentalidade anterior (medieval e antiga) não conheceu desta 
forma. Como poderíamos averiguar sucintamente este acontecimento, este projeto descobridor? (Cf. HEIDEGGER, 2006, §69b, p. 451). Como poderíamos ontologicamente - e não historicamente - apresentar este momento de decisão?

Atentemos para alguns momentos da decisão moderna pela ciência e pela razão visando captar o traço ou jeito que, hoje, se tornou corriqueiro.

\subsection{A mente concipio de Galileu}

Os primeiros grandes cientistas da época moderna perceberam que a tarefa da ciência não seria a de obedecer aos objetos, à natureza, mas de desenvolver outro comportamento. Compreenderam que, se por um lado não se deparam com o nada, isto é, contam com algo - a natureza dada por outro, perceberam que não é esta natureza pura e simplesmente que lhes interessa. Compreenderam a tarefa da ciência moderna como uma construção, como uma interpretação dos fatos ou dos elementos que se oferecem aos sentidos. "A ciência é, com efeito, interpretação dos fatos. Por si mesmos eles não nos dão a realidade, ao contrário, ocultam-na, isto é, nos propõem o problema da realidade" (ORTEGA Y GASSET, 1989, p. 23). Toda ciência "tem de ser uma construção e não um mero espelho dos fatos" (ORTEGA Y GASSET, 1989, p. 31). A compreensão da ciência como construção consiste numa tarefa imaginativa, num trabalho, por assim dizer, mental. É o que se cunhou no moto mente concipio, como dizia Galileu, no conceber na mente, gerar, imaginar, isto é, "teorizar". Ou, em outras palavras, impor à natureza este novo projeto de conhecimento, de saber. Grosso modo é este o projeto científico moderno.

Consiste ele em dois momentos: 1. Uma tarefa imaginativa, criadora: as hipóteses, por exemplo. No entanto, é preciso salientar: "Por isso Newton declarou: hypotheses non fingo, as hipóteses não foram inventadas arbitrariamente. Elas foram desenvolvidas a partir do plano da natureza e inscritas nele" (HEIDEGGER, 1986, p. 107). As hipóteses não foram aleatoriamente imaginadas. 2. O confronto do que foi imaginado, concebido na mente, com a natureza. Se casam uns com os outros, descobrimos a realidade que estava escondida na confusão dos fatos (Cf. ORTEGA Y GASSET, 1989, p. 26). Adiante explicitaremos um pouco mais este confronto e encaixe.

Galileu, no livro intitulado "Diálogo das novas ciências" (apud ORTEGA Y GASSET, 1989, p. 27) diz: "concebo por obra da minha mente um móvel lançado sobre um plano horizontal e retirado todo impedimento". Um móvel corresponde a um ente, um corpo, qualquer corpo. Este móvel 
concebido na mente, foi gerado num "lugar" não natural, um lugar livre de todo impedimento ou perturbação sensível e que possa permitir idealmente esta atividade imaginativa. Trata-se de uma imaginação racional, matemática, pura no sentido de não afetada por qualquer elemento da natureza mutável. Assim, "estritamente falando, não há ciência como investigação a não ser depois que a verdade tenha se tornado certeza da representação" (HEIDEGGER, 1986, p. 114). Galileu, então, começa por imaginar representar. A bem dizer, esta tarefa nunca ignora o confronto com a natureza e nem o pode. Pertence a ela imaginar como o plano ideal se realizará levando em conta os impedimentos oferecidos pela natureza, tais como, resistência do ar, gravidade, massa, composição dos materiais, etc. Dessa forma, não devemos confundir esta tarefa imaginativa como sendo independente de seu propósito, a saber, ordenar ou controlar os fenômenos naturais.

De forma tosca, podemos nos expressar assim: quando a suspeita de Galileu estiver razoavelmente organizada, ele a confrontará com a realidade, com os fatos, com os impedimentos que sempre encontramos na realidade natural. Assim, diante de uma infinidade de movimentos locais não somente de deslocamento - segundo o modo de ser de cada coisa natural (física aristotélica), Galileu elege como princípio um movimento que não existe no mundo natural. Tal eleição não é arbitrária. Consiste na focalização de um movimento, o deslocamento dos corpos no espaço, que pode se submeter à linguagem matemática, que pode ser descrito, controlado, previsto por esta mesma linguagem a priori, na imaginação. A posteriori este movimento eleito será testado, aplicado ao mundo natural. $\mathrm{E}$, desta forma, o cientista já saberá de antemão - este é o projeto - como os objetos se comportarão na natureza. Nós sabemos que pertence a esta aplicação a consideração de todos os impedimentos para que eles não afetem, ou afetem o mínimo possível, o móvel. Esta tarefa pertence ao imenso esforço desta ciência nascente e da continuidade de toda ciência: encontrar a fórmula, o modelo conveniente. O que isto significa? Que o modelo ideal gerenciará o conhecimento do mundo real, natural. Saber privilegiado. Teoria primeira! Mas para que será este modelo ideal aplicado ao mundo real? Nunca no sentido de averiguar se a teoria está correta, mas no sentido de constranger a natureza a responder a este modelo.

\subsection{A experimentação ou o casamento da mente com a natureza}

Um belo exemplo do comportamento do homem moderno nos é descrito por A. Koyré, no texto Galileu e a experiência de Pisa. A propósito de uma lenda (KOYRÉ, 1982, p. 204ss). Muito lentamente a novidade da intuição moderna foi se instalando. Podemos perceber isto melhor, 
relatando a experiência da queda dos corpos que Galileu realizou na cidade de Pisa. Se Galileu realmente efetivou tal projeto, isto não é o mais importante. O importante é o a priori que está em jogo no projeto de Galileu, a partir do qual podemos compreender a noção de móvel, de corpo e a necessidade de uma nova linguagem.

$\mathrm{Na}$ experiência de Pisa, Galileu buscou a prova para a falsidade da compreensão aristotélica acerca da queda dos corpos. Para tanto, ele já se apoiava numa nova maneira de ver e pensar. Galileu viu que "todos os corpos caem à mesma velocidade e que a diferença dos tempos de queda resulta somente da resistência da atmosfera, e não da diferença de natureza" (HEIDEGGER, 1992, p. 94), como pensava Aristóteles. Galileu lançou diversos corpos de diferentes materiais da torre de Pisa e constatou-se que eles não caíram ao mesmo tempo, mas com pequenas diferenças. Logo, a experiência não comprovou a tese de Galileu. No entanto, ele não modificou seu ponto de vista. Consequentemente, os espectadores agarraram-se ainda mais ao aristotelismo, discordando de Galileu. Galileu não obedeceu ao experimento? Foi ele um péssimo cientista? Os espectadores procuravam uma prova empírica, sensível, do que não podia ser provado desta maneira. A experiência de Galileu, de fato, não constitui uma prova, porque a perspectiva dentro da qual ele se insere antecede toda e qualquer prova esperada pelos físicos aristotélicos de então. Constitui-se mesmo como condição de possibilidade para alguma prova. Expliquemos mais.

Todos viram o mesmo "fato". No entanto tiraram conclusões diversas porque o interpretaram de modo diferente. O corpo é visto a partir de pontos de vista distintos. O conflito, então, não reside na experiência, mas no modo de ver, na teoria de base. Galileu sabe que os fatos não são meros fatos, mas que são previamente encontrados de determinada forma, interpretados, isto é, que atendem antecipadamente a um ponto de vista. Ele sabe que o fato só tem sentido como re-apresentação de um a priori. Por isso ele não altera a sua convicção, já que ela não se baseia na experiência sensível. O decisivo que orienta o encontro com os fatos não é "observável" nos fatos por meio dos sentidos ou da empiria, pois é ele que faz ver e interpretar os fatos. As divergências que aqui aparecem não são discordâncias acerca de aspectos particulares. A divergência é "em relação à essência do corpo e à natureza do seu movimento" (HEIDEGGER, 1992, p. 95).

Galileu entendeu antecipadamente a queda dos corpos. Esta afirmação deve ser antes compreendida do que experimentada, pois ela vale "num caso abstrato e fundamental de movimento no vácuo" (KOYRÉ, 1982, p. 204), onde um corpo em queda não sofre nenhuma resistência que altere sua velocidade ou seu percurso. Galileu não tinha necessidade nenhuma da experiência para saber que os corpos chegariam ao solo em 
tempos iguais, o que não aconteceu devido à resistência do ar sobre os mesmos e os materiais empregados. A experiência "empírica", neste raciocínio, possui algo de irrelevante. Antecipadamente Galileu reconheceu a queda (movimento) dos corpos de modo universal, como pertencendo a todos os corpos materiais em geral, e não de um corpo particular segundo sua natureza. A estrutura do matemático está presente, mas de um modo especial e determinante, como aquilo que antecipadamente se espera dos corpos e que se torna matematicamente visível e passível de descrição e fixação em caracteres físico-matemáticos. Pois o modo de reconhecer este movimento e os corpos movidos está de acordo com outro lugar que não é mais a natureza física. Por ora este lugar é o vácuo (que, de fato, inexiste na natureza física, sendo possível apenas na mente), como uma idealidade onde o movimento uniforme e retilíneo acontece da mesma forma para todo e qualquer corpo. Esta concepção puramente matemática independe da realidade sensível. Dentro desta linha que percebe a novidade de Galileu é que Koyré defende a tese de que a experiência de Pisa com a queda dos corpos, efetivamente nunca aconteceu (KOYRÉ, 1982, p. 205.). Afinal, Galileu sabia, como expôs Koyré em seu texto Galileu e a revolução científica do século XVII, que

a necesse determina o esse. A boa física é feita a priori. A teoria precede o fato. A experiência é inútil porque, antes de toda experiência, já possuímos o conhecimento que buscamos. As leis do movimento (e do repouso), (...) são leis da natureza matemática. (KOYRÉ, 1982, p. 193-194).

A imaginação visa o encaixe, isto é, objetiva a interpretação da natureza numa unidade do ser espaço-temporal. Por isso, na linguagem deste mesmo autor, em seu artigo, Do mundo do "mais ou menos" ao universo da precisão trata-se da "conversão da inteligência teórica ao real" ou "não é do desenvolvimento espontâneo das artes industriais por aqueles que as exercem, mas da conversão da teoria na prática" (KOYRÉ, 1991, p. 275). A "conversão" aludida não significa o abandono da teoria em prol da prática. Isto equivaleria a um retorno para o enfoque empirista, qualitativo, obediente ao objeto ou à natureza. A conversão possui o caráter de uma imposição, um predomínio, um constrangimento, isto é, o real, a natureza, é interpretada, construída - ou reconstruída - a partir desta orientação teórica, deste plano prévio racional.

A conversão da teoria na prática nos remete a uma nova compreensão de prática. Agir no mundo, na natureza, não é mais agir 
seguindo a natureza, mas é guiar sua ação pela razão, pelo modelo, por um planejamento previamente calculado. A razão, como dizia Kant, rege a experiência que se direciona à natureza na qualidade de juiz e nunca buscando nesta a última palavra, mas, ao contrário, sentenciando-a. No entanto, como acontece esta relação? Este casamento da teoria imaginada com o mundo, com a natureza? Esta conexão nunca é um encaixe qualquer. Somente a partir desta conexão é que se descobre a natureza conhecida pela ciência física, por exemplo, e se descortina o horizonte da práxis moderna. Esta conexão, encaixe ou casamento, em sua cunhagem moderna, liga-se à descoberta da natureza como res extensa, dos entes como corpos simplesmente dados ou evidentes, independentes de sua relação polissêmica com o ser humano. Esta natureza é dotada de propriedades igualmente extensas, passíveis de medição exata que atendem a leis prévias, e que podem ser descritas ou fixadas graças à descoberta da matemática como a linguagem privilegiada para este fim. Percebemos o quanto uma natureza concebida qualitativamente - onde inclusive as medições não eram ignoradas - cede lugar a uma natureza quantitativa, extensa, que se mantém em todas estas alterações como permanência constante (Cf. HEIDEGGER, 2006 , p. $\$ 19$, p. 153). O ser, a substância, o fundamento, é interpretado como a permanência ou a constância do ser simplesmente dado. Esta interpretação não é retirada dos entes mundanos ("modo empírico"), mas ditada ou prescrita ao mundo (Cf. HEIDEGGER, 2006, §21, p. 148). A ciência física preocupa-se em construir

um sistema de manipulações subjetivas que seja coerente. Algo é real para a física na medida em que se encaixa em certas operações de medida. A realidade cósmica foi substituída pelo rito humano da métrica. (ORTEGA Y GASSET, 1958, p. 78-79).

Dessa forma, a prática pode ser descrita como uma prática calculada. Assim, não qualquer prática é o que interessa no horizonte da ciência moderna e, por extensão, no horizonte do predomínio da tecnologia funcionalidade cibernética - mas aquela prática que atende ao projeto moderno de descoberta da natureza.

\subsection{A ação a partir da experimentação: ação planejada}

A partir disto já antevimos como será interpretada a ação válida, desejada e/ou previsível. Por certo, ela se restringe - de início - ao modo de ser científico nascido na e a partir da física moderna. Mas quando intuímos que a ciência, por sua vez, transformou-se no modelo de existência, também antevimos o alargamento, isto é, o ultrapassamento de suas fronteiras para 
outros setores da vida, para os demais saberes e para as práticas cotidianas, fenômeno expresso, por exemplo, no conceito de "naturalismo" que será sucintamente apresentado mais adiante. $\mathrm{O}$ que, de alguma maneira, não atender a este modelo, não corresponde à ação ideal e desejável. Por isso, torna-se útil para nossa reflexão uma observação do comportamento humano presente na experimentação, tal como a ciência física moderna a compreendeu. No texto intitulado A contribuição científica da renascença e, noutro, Kant, Hegel e Dilthey, nos informam, respectivamente, A. Koyré e Ortega y Gasset, sobre o modo de fazer ciência de Galileu:

Galileu sabe (...) que o experimentum é preparado, que o experimentum é uma pergunta feita à natureza, uma pergunta feita numa linguagem muito especial, na linguagem geométrica e matemática. Sabe que não basta observar o que se passa, o que se apresenta normalmente e naturalmente aos nossos olhos; sabe que é preciso saber formular a pergunta e, além disso, saber decifrar e com-preender a resposta, ou seja, aplicar ao experimentum as leis estritas da medida e da interpretação matemática" (KOYRÉ, 1982, p. 54).

O que interessa a Galileu não é, pois, adaptar suas ideias aos fenômenos, mas, ao contrário, adaptar os fenômenos por meio de uma interpretação segundo certas ideias rigorosas e a priori, independentes do experimento, em suma, a formas matemáticas (ORTEGA Y GASSET, 1958, p. 72-73).

Intui-se, imagina-se primordialmente que o livro da natureza é escrito em caracteres geométricos. Os fenômenos, que correspondem ao ente sensível, terreno e imperfeito, devem se adaptar a esta linguagem rigorosa. $\mathrm{Na}$ experiência, a natureza é forçada a responder de tal ou tal modo, conforme a abertura própria do projeto matemático. E se, mediante a experimentação, os fenômenos da natureza sensível não corresponderem à natureza ideal, previamente acertada, pior para eles. De acordo com isto, diz Toscanelli:

Que os princípios da doutrina do movimento sejam verdadeiros ou falsos importa-me pouquíssimo. Pois que, se não são verdadeiros, finja-se que o sejam conforme havíamos suposto, e pois, tome-se (como verdadeiras) todas as outras especulações derivadas destes princípios, não como coisas confusas, mas como pura geometria. Eu finjo ou suponho que algum corpo ou 
ponto se mova para baixo e para cima, numa clara relação e horizontalmente num movimento equânime. (...) Se pois as bolas de chumbo, de ferro, de pedra não observarem aquela suposta relação, o prejuízo será delas, e nós diremos que não falamos disso.(apud ORTEGA Y GASSET, 1958, p. 72-73).

Como esta citação nos remete à experiência de Galileu em Pisa, descrita por Koyré! Desta forma, se a realidade sensível não se comportar de acordo com nossa construção mental, pior para a realidade. A experimentação será refeita, pois a natureza deve responder àquilo a que foi interpelada. $\mathrm{O}$ mundo sensível não tem saída. No sentido aludido, então, o desenvolvimento da ciência moderna, segundo o artigo As origens da ciência moderna, uma nova interpretação, não se deve a um desvio da teoria para a prática, não se deve a um interesse simplesmente prático e oposto a uma suposta atitude contemplativa e teórica antigas (Cf. KOYRÉ, 1982, p. 67-68). Este desenvolvimento se deve ao predomínio da razão, da mente, da imaginação.

A maneira pela qual Galileu concebe um método científico correto implica uma predominância da razão sobre a simples experiência, a substituição de uma realidade empiricamente conhecida por modelos ideais (matemáticos), a primazia da teoria sobre os fatos. (KOYRÉ, 1982, p. 74).

Dizendo melhor: numa experimentação a natureza, de um modo ou de outro, sempre responde. Mas como se mostra esta resposta a partir do procedimento científico moderno? Quando a resposta não corresponde ao modelo prévio, calculado, planejado, o cientista retorna ao modelo e o reformula. Ele não deve se deixar perturbar pelos fenômenos naturais que contradizem o que ele esperava. Ele retorna porque a resposta-recusa da natureza não era a resposta que interessava, não era a resposta conveniente. $\mathrm{O}$ cientista poderia abandonar o modelo que orientou toda a experimentação e ir atrás da natureza (como um empirista pré-kantiano) buscando que ela lhe fornecesse a orientação. Mas então ele não seria cientista em sentido moderno. E a natureza lhe forneceria tantos modelos e orientações quantos modos de ser ou entes existissem. Não haveria acordo entre as pesquisas, por exemplo, pelo menos se levarmos em conta os princípios que orientam a ciência moderna, como a busca da exatidão ou da precisão. Qual é, então, a resposta que interessa, aquela que deve ser buscada, aquela que a natureza deve dar e que não pode recusar, aquela que em sentido privilegiado mostrará a natureza buscada? A resposta que interessa é aquela que corresponde ao projeto físico-matemático de interpretação da natureza, ou 
seja, que atende ou se encaixa em leis físico-matemáticas, universais, duráveis, permanentes, o mesmo para todos, precisas. Estes aspectos de exatidão, precisão, durabilidade, previsibilidade, etc., e que apenas podem ser expressos e fixados por meio da física-matemática, correspondem à interpretação do mundo como res extensa, como extensão, ou seja, aos aspectos quantitativos e quantificáveis da realidade. Os qualitativos, a princípio, não se submetem a esta nova metodologia. Eles, em geral e de início, perdem o "selo" de validade.

\section{Considerações finais: a ação vantajosa}

A que ponto chegamos com nossas reflexões? Nosso objetivo era o de tornar visível uma determinada compreensão de prática, aquela que experimentamos, sem termos muita consciência disso, no predomínio técnico-científico. Focamos rudemente o desenvolvimento da moderna ciência da natureza, buscando alguns procedimentos que poderiam nos orientar. Por certo, encontramos uma prática organizada, planificada, a serviço da razão teórica e que impõe ao real um plano seu. No entanto, reside certo silêncio de nossa parte a respeito das condições históricas e metafísicas responsáveis pelo ultrapassamento dos limites da ciência física rumo a outros campos nascentes do saber e que buscavam, por sua vez, a cientificidade. Na pergunta pelo ser da ciência reside o desenvolvimento destes problemas. Talvez a pergunta fundamental possa ser assim expressa: por que a ciência se tornou nosso modo de ser mais desejado? Trata-se de nosso destino histórico, de uma destas figuras do ser que constrói uma época e a domina quase que à revelia das vontades individuais?

Nas próximas linhas acenaremos, por assim dizer, para a tomada de consciência destes problemas os quais nos convocam a novos aprofundamentos. Como já o dissemos, durante o século XIX, os princípios que orientaram a pesquisa científica da natureza estenderam-se para o ser humano e para a vida social. Como isso se deu? A razão foi superestimada? A indústria, o lazer, as instituições, as ciências humanas, etc., encontraram na física seu "modelo de ciência" e procuraram imitá-la. Esta imitação significou a aplicação aos mais diversos campos da vida humana dos princípios da certeza, segurança, controle, repetição, previsibilidade, universalidade, estabilidade ou permanência. Os conceitos sociais, por exemplo, deveriam, à sua maneira, ser tão precisos e seguros como os conceitos físico-matemáticos aplicados ao domínio da natureza extensa. Da mesma forma os psicológicos. Mas, qual a consequência "epistemológica" deste comportamento? Aspectos qualitativos do ser humano, como os 
fenômenos psíquicos, foram interpretados "físicamente" ou como variações dos fenômenos físicos. A este modo de proceder denominou-se "naturalismo" nos inícios do século XX. Segundo Husserl, em seu ensaio de 1913 A filosofia como ciência de rigor,

O Naturalismo resulta do descobrimento da Natureza como unidade do Ser no tempo e no espaço, segundo leis exatas naturais. O Naturalismo propala-se na medida da realização progressiva desta ideia em ciências naturais, que constantemente se multiplicam, fundamentando uma superabundância de conhecimentos rigorosos. (...) $\mathrm{O}$ cientista dedicado às Ciências naturais tende a considerar tudo como natural, (...) errando, por conseguinte, na interpretação daquilo que não possa ser considerado desta maneira. Portanto, passando a tratarmos em especial do Naturalista, este não depara senão com a Natureza, a começar pela natureza física. Tudo o que é, ou é, ele mesmo físico, ou, apesar de psíquico, é mera variação dependente do físico, na melhor das hipóteses, 'fato paralelo, concomitante', secundário. Tudo que é, é de natureza psico-física, inconfundivelmente determinado segundo leis firmes. (HUSSERL, 1958, p. 9).

Haveria muito a dizer a partir desta citação. No entanto, frisaremos apenas, e sucintamente, o aspecto de predomínio da mentalidade física que sobrepujou outros saberes. Observemos, então, o pressuposto positivista sobre a teoria e a prática, citado por Ortega em seu livro Que é filosofia? e que exemplifica esse poder naturalista. Assim, no século XIX, sobretudo na segunda metade, qual será o sentido do conhecimento, do conhecimento desejável e "verdadeiro"? Qual será a ação desejável? Augusto Comte exprimiu essa situação na fórmula: "Science, d'où prévoyance; d'où action. Isto é: o sentido do saber é o prever, e o sentido do prever é tornar possível a ação. Daí resulta que a ação - entenda-se vantajosa - é que define a verdade do conhecimento" (apud ORTEGA Y GASSET, 2007, p. 34).

A ação, a prática, vem em primeiro lugar. O que aparentemente chega por último - a prática - possui precedência ontológica. Aqui é também o caso. Esta compreensão de ação confere sentido a toda previsão, ou seja, a todo planejamento das atividades. Nisso consiste o saber: na prévisão das ações. O saber consiste na previsão da ação tornando-a certa e segura, retirando dela todo caráter aleatório, imprevisível e plural. Como este entendimento de prática se distingue daquele, já apresentado, que compreende o ser humano, primariamente e antes de tudo, como ocupação, como lida! Aqui uma ocupação determinada alçou e concedeu-se o direito 
(por que e como este direito se instalou?) de ser a atividade modelar, exemplar e exclusiva. Desta forma, o saber - e agora todo o saber - já está pré-orientado segundo determinada metodologia: antes de qualquer ação de fato, já se sabe o que e como fazer.

Mas não se trata de qualquer ação, não vale qualquer atividade. Interessa a atividade vantajosa, aquela que realiza e exterioriza a ação correspondendo à previsibilidade. A atividade vantajosa mora previamente em todo este esforço intelectual como uma "ideia fixa" que permanece, no entanto, obscura, oculta e silenciada na reflexão. Este processo vantajoso não sente a necessidade de pensar a si mesmo. Então não se trata, aqui, de alguma vantagem subjetiva que se poderia obter na convivência ou na lida com as coisas.

O positivismo, em seu primado prático, não contradiz o princípio da razão teórica que mora no começo da ciência moderna? Esta resposta deve ser buscada no modo como a descoberta da natureza como extensão foi conquistada racionalmente e exclusivamente, bem como no porquê e como semelhante compreensão tornou-se preponderante e, como evidência de toda pesquisa e de todo saber, alastrou-se e se alastra para todos os âmbitos do saber. Constatamos que no positivismo já se calou aquela inquietação, aquele espírito imaginativo que contaminou os primeiros grandes cientistas. Não aparece mais aquele esforço de Galileu ou de Toscanelli, conscientes de suas dificuldades, no sentido de construir uma nova linguagem e de tornar possível um novo modo de relacionamento com a natureza. $\mathrm{O}$ positivismo do século XIX - e da primeira metade do século XX -, mais do que uma escola filosófica ou doutrina, usufrui da vitória da ciência, do cientificismo, e aplica e estende por todo o globo seus trunfos nos fenômenos conhecidos como naturalismo, eurocentrismo, europeização do mundo, neocolonialismo ou imperialismo. Nele, a perspectiva de domínio da natureza e da vida por meio da ciência, bem como a compreensão da ciência como meio ou instrumento de ordem, de estabilidade, de segurança, enfim, de conhecimento, tornaram-se, em geral, evidências inquestionáveis. Toda crítica a esta nova ordem, grosso modo, tornou-se secundária. As observações críticas à ciência, à indústria, à burguesia, à moral cristã, ao trabalho, ao capitalismo, ao socialismo, etc., possuem algo de secundário, visando antes alguma forma de arrumação, segundo esta ou aquela perspectiva. Por exemplo, a ciência é bastante crítica acerca de suas pesquisas, de seus objetos, de sua utilidade social. Mas tamanha crítica não põe a si própria em questão. Por certo, questionamentos desta ordem, que mais se assemelham a uma arrumação das coisas dentro de uma grande ordem, não esgotam nem expressam alguns dos mais radicais posicionamentos filosóficos surgidos nesta época. 
A ação vantajosa, de um ponto de vista ontológico, não é adequadamente compreendida quando a consideramos como o resultado pragmático de alguma ação. Pois ela se mostra, antes, como o princípio de toda atividade. A partir disso, o pensar já se tornou uma peça funcional, um raciocínio prático, produtivo, a serviço da segurança, estabilidade, conforto. A previsão não poderia ser algo distinto do que o planejamento de ações seguras e acertadas, previsíveis, estáveis, visando ou confirmando o "conforto" prático e teórico, ou seja, onde todas as surpresas ou pluralidade de sentidos e de possibilidades da práxis sejam excluídas. A surpresa e o imprevisível devem ser continuamente abolidos porque colocam em perigo - tanto num sentido ontológico quanto num sentido imediatamente prático este modo de vida desejado. Vemos, então, que a prática enquanto esta ação vantajosa corresponde à teoria e vice-versa. Aquele saber nascido nos primórdios da modernidade para o conhecimento e controle da natureza extensa como o que pode ser medido e calculado, sofreu um conjunto de modificações e, agora, é aplicado ao homem e ao mundo social em todos os seus aspectos. Um sintoma deste acontecimento mostra-se no esforço continuado das ciências humanas que, desde o século XIX, lutam para construir um conjunto de métodos distintos daqueles que caracterizaram e caracterizam as ciências naturais. De forma exagerada, podemos dizer que tudo ou quase tudo deve seguir o modelo científico forjado na alvorada da modernidade extrapolando os limites próprios do ente físico ou natural. Tornar visível este modelo conveniente, ou seja, "teorizar", soa mal. Os princípios e causas já não interessam porque foram substituídos por funções "cibernéticas" (HEIDEGGER, 1983, p. 73). O que importa é a funcionalidade, as hipóteses de trabalho, provisórias e duradouras. Encontramos, dessa forma, o primado funcional tecnológico - a prática planejada. Pois o pragmatismo não visa qualquer prática, qualquer ação, mas a que convém.

Para finalizar, e a título de provocação, trazemos um pequeno texto do filósofo M. Heidegger. No início de sua Carta sobre o Humanismo ele expressa uma das tarefas de nosso tempo, senão a tarefa principal. Eis o texto:

De há muito que ainda não se pensa, com bastante decisão, a Essência do agir. Só se conhece o agir como a produção de um efeito, cuja efetividade se avalia por sua utilidade. A Essência do agir, no entanto, está em con-sumar. Con-sumar quer dizer: conduzir uma coisa no sumo, à plenitude de sua Essência. Levála a essa plenitude, producere. (HEIDEGGER, 1967, p. 23-24). 


\section{Referências}

FLUSSER, V. Da religiosidade. A literatura e o senso de realidade. São Paulo: Escrituras Editora, 2002.

. Filosofia da caixa preta. Ensaios para uma futura filosofia da fotografia. Rio de Janeiro: Relume Dumará, 2002.

- O mundo codificado. Por uma filosofia do design e da comunicação. São Paulo: Cosac Naify, 2007.

FOUCAULT, M. Vigiar e punir. História da violência nas prisões. Petrópolis: Vozes, 1988.

HEIDEGGER, M. Carta sobre o humanismo. Trad. Emmanuel Carneiro Leão. Rio de Janeiro: Tempo brasileiro, 1967.

. Chemins qui ne mènent nulle part. Paris: Gallimard, 1986.

. "O fim da filosofia e a tarefa do pensamento". In: Conferências $e$ escritos filosóficos. São Paulo: Abril Cultural, 1983. (Col. Os pensadores).

2002. . "A questão da técnica". In: Ensaios e conferências. Petrópolis: Vozes,

. "O conceito de tempo". Cadernos de tradução, n. 2, DF/USP, 1997.

. Ser e tempo. Petrópolis: Vozes, 2006.

. Que é uma coisa? Doutrina de Kant dos princípios transcendentais. Lisboa: edições 70, 1992.

HUSSERL, E. Filosofia como ciência de rigor. Atlântica, Coimbra: Ed. Tipo. 1965.

KANT, Immanuel. Crítica da razão pura. Lisboa: Fundação Calouste Gulbenkian, 1994.

KOYRÉ, Alexandre. Estudos de História do pensamento científico. Rio de Janeiro: Ed. Forense Universitária, 1982.

. Estudos de História do pensamento filosófico. Rio de Janeiro: Forense Universitária, 1991.

NICOLESCU, Basarab. O Manisfesto da transdisciplinaridade. São Paulo: TRIOM, 1999.

ORTEGA Y GASSET, J. Kant, Hegel, Dilthey. Madrid: Revista de Ocidente, 1958.

. Que é filosofia? Lisboa: Biblioteca Editores independentes, 2007. . Em torno a Galileu. Esquema das Crises. Vozes : Petrópolis, 1989. 